\title{
Varicose veins in hairdressers and associated risk factors: a cross-sectional study
}

\author{
Chao-Lin Chen ${ }^{1,2}$ and How-Ran Guo $2,3^{*}$
}

\begin{abstract}
Background: Varicose veins $(\mathrm{W})$ cause not only cosmetic problems but also clinical symptoms such as pain of the affected limbs. Whereas an occupation associated with orthostasis has been recognized as a risk factor of W, epidemiological studies on working populations are limited. We conducted a study to identify the risk factors of lower limb W among hairdressers in Taiwan and evaluate their effects, with a focus on long-term standing at work.

Methods: We recruited participants from members of a hairdressers union in southern Taiwan and conducted a questionnaire survey. Data on demographic characteristics, body weight and height, work history, medical history, and other potential related factors were collected from each participant.

Results: A total of 182 hairdressers participated in the survey, and 44 (24.2\%) had lower limb W. Uni-variate analyses showed that hairdressers with lower limb W tended to be older (49.3 vs. 44.7 years, $p=0.032$ ), have a family history of W $(25.6 \%$ vs. $9.9 \%, p=0.011)$, doing housework in standing position ( $86.4 \%$ vs. $71.0 \%, p=0.042)$, have a longer work history (30.5 vs. 24.0 years, $p=0.005$ ), and stand longer at work (213.9 vs. 176.0 hour/month, $p=0.008$ ). In multivariate analysis, in hairdressers $\leq 45$ years old, the only significant risk factor was a family history of $\mathrm{W}$ (odds ratio $[\mathrm{OR}]=11.9$, $95 \%$ confidence interval $[95 \% \mathrm{Cl}]=1.1-133.5)$. In hairdressers $>45$ years old, the risk factors included standing working for $>260$ hours per month $(\mathrm{OR}=31.8,95 \% \mathrm{Cl}=1.8-566.5)$ and working as a hairdresser for $>30$ years (for 31-42 years, $\mathrm{OR}=10.9,95 \% \mathrm{Cl}=1.6-73.8$; for $\geq 43$ years, $\mathrm{OR}=12.0,95 \% \mathrm{Cl}=1.6-88.5)$.
\end{abstract}

Conclusions: In hairdressers $\leq 45$ years old, family history of $\mathrm{W}$ is a major risk factor for developing lower limb $\mathrm{W}$, while in those who are $>45$ years old, the effects of occupational risk factors are more prominent.

Keywords: Varicose veins, Hairdressers, Occupation, Standing, Epidemiology

\section{Background}

Varicose veins (VV) may cause discomfort of the affected limbs and cosmetic problems, which often need surgery or other invasive treatments, consuming health care budget [1] and reducing productivity of the workers. This illness was due to venous valves insufficiency, with age as an aggravating and risk factor and family history as an important risk factor [2]. Other risk factors include female gender, the number of children given birth, body weight, constipation, and history of venous thrombosis [2-7]. Prolonged standing at work had been suspected

\footnotetext{
* Correspondence: hrguo@mail.ncku.edu.tw

${ }^{2}$ Department of Occupational and Environmental Medicine, National Cheng

Kung University Hospital, Tainan, Taiwan

${ }^{3}$ Department of Environmental and Occupational Health, National Cheng

Kung University, 138 Sheng-Li Road, 70428 Tainan, Taiwan

Full list of author information is available at the end of the article
}

as an aggravating or risk factor of $\mathrm{VV}$ of lower limbs, but findings in previous studies were not consistent [4].

For hairdressers, prolonged standing is an inevitable part of work. A survey on hairdressers in Tehran, Iran showed a VV prevalence rate of $35.62 \%$ [8], but the relationship between prolonged standing at work and VV was not studied. Therefore, we conducted a study in southern Taiwan to evaluate whether prolonged standing at work can increase the risk of developing VV.

\section{Methods \\ Data collection}

We recruited participants from members of a local union of hairdressers in southern Taiwan and conducted a questionnaire survey. The questionnaire had been validated by an expert panel of four researchers before its use. The panel included an occupational medicine specialist, 
an industrial hygienist, an occupational nurse, and a surgeon, and each member reviewed the draft independently. The first author ( $\mathrm{C}-\mathrm{L} \mathrm{Chen})$ finalized the questionnaire according to the comments from the panel. Data on demographic characteristics, body weight and height, work history, daily work hours (including hours of standing), monthly work days, current morbidity, medical history (including VV, deep venous thrombosis, constipation [defined as weekly defecation less than 3 times], surgery, and major trauma), family history (including family history of VV), and activities after work (including regular sport activities, part-time job, and doing housework in standing position) were collected from each participant by the use of self-administered questionnaire.

To evaluate the effects of prolonged standing at work, we calculated the hours of standing in working each month as daily standing work hours multiplied by monthly work days. For example, an employed hairdresser who worked in standing position about 7 hours a day for 24 day a month (taking every Sunday and every other Saturday off as the maximum work days allowed by law in Taiwan) had $7 \times(30-4$ [Sundays] -2 [Saturdays] $)=168$ hours of standing in working each month. Likewise, a self-employed hairdresser who worked in standing position about 4 hours a day for almost every day (30 days a month) had $4 \times 30=120$ hours of standing in working each month.

\section{Data analysis}

We evaluated differences in continuous variables between those with and without lower limb VV using the Student's $t$ test or Mann-Whitney $\mathrm{U}$ test and differences in categorical variables using the Chi-square test or Fisher's exact test. We conducted further analyses using multivariate logistic regressions. The models included variables that appeared to be significant predictors of lower limb VV in the uni-variate analyses. According to the results of initial analyses, we divided the participants into two age groups ( $\leq 45$ years old and $>45$ years old) and conducted separate analyses to adjust for the effects of age and demonstrate its effect modification of other risk factors. All statistical analyses were performed using SPSS 12.0 (SPSS Inc., Chicago, IL, USA) at the two-tailed significant level of 0.05 .

\section{Ethics statement}

This study was ethically approved by the Grant Review Committee of the Council of Labor Affairs of the Taiwan government. At the time when this study was conducted, the Regulations on Human Trials have not been implemented by the Taiwanese government. We conducted the study according to the principles expressed in the Declaration of Helsinki and analyzed the data anonymously. All participants submitted a written informed consent to participate in the study.

\section{Results}

A total of 182 hairdressers participated in the study, including 166 women (91.2\%), 15 men (8.2\%), and 1 who did not provide information on the gender. The average age was 45.8 , but 11 participants did not provide information on the age. There were 44 cases of lower limb $\mathrm{VV}$, corresponding to a prevalence of $24.2 \%$, and the average duration of the illness was 16.2 years (standard error $[\mathrm{SE}]=1.7$ years).

In comparison with hairdressers without the disorder, those who had lower limb VV had a longer work history (the number of years of working as a hairdresser was 30.5 vs. 24.0 years, $p=0.005)$, an older age ( $49.3 v$ s. 44.7 years, $p=0.032$ ), and more hours of standing in working as a hairdresser each month (213.9 vs. 176.0 hours, $p=0.008$ ) (Table 1). The body mass index (BMI), number of childbirths, and number of hours doing housework in standing position did not appear to be significant predictors of lower limb VV (all with $p>0.05$ ). Among the categorical variables, significant predictors included having a family history (parents, grandparents and siblings) of VV $(25.6 \%$ vs. $9.9 \%, p=0.011$ ) and doing housework in standing position $(86.4 \%$ vs. $71.0 \%, p=0.042)$ (Table 2). Gender, age stratum, having constipation, regular exercise, and habits of smoking and drinking did not appear to be significant predictors of lower limb VV (all with $p>0.05$ ). We also tried analyzing the number of childbirths as a categorical variable $(0,1,2,3$, and $>3)$, but it still did not appear to be a significant predictor.

When we divided participants into four age groups ( $\leq 35$ years, $36-45$ years, $46-55$ years, and $>55$ years), we found that in the age group 46-55 years, hairdressers with lower limb VV had a longer work history (33.6 vs. 29.0 years, $p=0.044$ ) (Table 3 ). Differences in work history in the other age groups did not reach statistical significance (all with $p>0.05$ ), indicating effect modification, and therefore we conducted further stratified analyses by age and use 45 years old as the cut-off.

In the multivariate analyses, a family history was the only significant predictor of lower limb VV identified in participants $\leq 45$ years old in our study $(\mathrm{OR}=11.9,95 \%$ $\mathrm{CI}=1.1-133.5$ ) (Table 4). In the older participants ( $>45$ years old), significant predictors included standing at work 261-360 hour/month $(\mathrm{OR}=31.8,95 \% \mathrm{CI}=1.8$ $566.5)$ and working as a hairdresser for $>30$ years (31-42 years, $\mathrm{OR}=10.9,95 \% \mathrm{CI}=1.6-73.8 ; 43-57$ years, $\mathrm{OR}=$ $12.0,95 \% \mathrm{CI}=1.6-88.5$ ), but a family history was not a significant predictor after adjusting for other variables $(\mathrm{OR}=$ 1.6, $95 \% \mathrm{CI}=0.4-7.1$ ) (Table 5).

\section{Discussion}

Prevalence

The reported prevalence rates of VV differed enormously in previous studies, ranging from $2 \%$ to $56 \%$ in men and 
Table 1 Comparison of continuous variables between hairdressers with and without lower limb varicose veins (VV)

\begin{tabular}{llll}
\hline Variable & With VV & Without VV & M value* \\
& Mean (SE) & Mean (SE) & 0.005 \\
\hline Work history (year) $(\mathrm{n}=167)$ & $30.5(1.9)$ & $24.0(1.2)$ & $44.7(1.1)$ \\
Age (year) $(\mathrm{n}=171)$ & $49.3(1.6)$ & $23.0(0.3)$ & 0.032 \\
Body mass index $\left(\mathrm{kg} / \mathrm{m}^{2}\right)(\mathrm{n}=170)$ & $23.5(0.6)$ & $176.0(7.6)$ & 0.407 \\
Monthly standing work hours (hour) $(\mathrm{n}=135)$ & $213.9(11.3)$ & $2.14(0.1)$ & 0.008 \\
Childbirth (time) $(\mathrm{n}=126)$ & $2.46(0.2)$ & $10.1(1.2)$ & 0.105 \\
Standing housework** (hour/week) $(\mathrm{n}=109)$ & $12.3(2.1)$ & & 0.334 \\
\hline
\end{tabular}

*two-sample $t$ test; **for those who do any standing housework.

Table 2 Comparison of categorical variables between hairdressers with and without lower limb varicose veins (VV)

\begin{tabular}{|c|c|c|c|}
\hline Variables & $\begin{array}{l}\text { With VV } \\
\text { N (\%) }\end{array}$ & $\begin{array}{l}\text { Without VV } \\
\mathrm{N}(\%)\end{array}$ & $p$ value \\
\hline Total & $44(24.2)$ & $138(75.8)$ & \\
\hline Sex & & & $0.529 *$ \\
\hline Women & $42(25.3)$ & $124(74.7)$ & \\
\hline Men & $2(13.3)$ & $13(86.7)$ & \\
\hline \multicolumn{4}{|l|}{ Age (year) } \\
\hline$\leq 35$ & $3(9.4)$ & $29(90.6)$ & \\
\hline $36-45$ & $12(48.8)$ & $31(51.2)$ & \\
\hline $46-55$ & $10(23.2)$ & $33(76.8)$ & \\
\hline$>55$ & $15(34.9)$ & $28(65.1)$ & \\
\hline Family history of W & & & $0.011^{* *}$ \\
\hline Yes & $11(47.8)$ & $12(52.2)$ & \\
\hline No & $32(22.7)$ & $109(77.3)$ & \\
\hline Constipation & & & $0.192^{* *}$ \\
\hline Yes & $6(37.5)$ & $10(62.5)$ & \\
\hline No & $38(22.9)$ & $128(77.1)$ & \\
\hline Regular sport activities & & & $0.607^{* *}$ \\
\hline Yes & $21(26.6)$ & $58(73.4)$ & \\
\hline No & $23(23.2)$ & $76(76.8)$ & \\
\hline Smoking & & & $0.764^{*}$ \\
\hline Yes & $3(18.8)$ & $13(81.2)$ & \\
\hline No & $41(25.3)$ & $121(75.7)$ & \\
\hline Drinking & & & $0.564^{*}$ \\
\hline Yes & $3(17.6)$ & $14(82.4)$ & \\
\hline No & $41(27.0)$ & $111(73.0)$ & \\
\hline Standing housework & & & $0.042^{* *}$ \\
\hline Yes & $38(29.0)$ & $93(71.0)$ & \\
\hline No & $6(13.6)$ & $38(86.4)$ & \\
\hline
\end{tabular}

*Fisher's exact test; **Pearson's chi-square test.
$1 \%$ to $73 \%$ in women $[2,3]$, probably affected by age, gender, race, and case definition. Of the studies conducted in Asia, one on 541 Japanese women observed a prevalence rate of $45 \%$, including the mildest to the worst type of $\mathrm{VV}$ [5]. A study in the Shanghai area of China on 30712 workers more than 15 years old in various industries observed a prevalence rate of $8.39 \%(\mathrm{~N}=2577)$ of lower limb VV [6]. The 24.2\% prevalence rate of lower limb VV in hairdressers in our study was within the reported range.

\section{Family history of varicose veins}

Our study found that having a family history of VV was a risk factor in the younger group ( $\leq 45$ years old), but the effect was not statistically significant in the older group (>45 years old). Similar results was observed in a study of 541 Japanese women, which found a greater proportion of having a family history in the younger patient group (25-39 years old, 59\%) than in the older patient group (>60 years old, 27\%) [5]. Some other studies also showed that a family history of $\mathrm{VV}$ was a major risk factor [7,9-11], and a study conducted by Cornu-Thenard et al. demonstrated that the risk increased dramatically in relation to the number of parents with VV [12]. Accordingly, we inferred that having a family history is a major risk factor of lower limb VV in the younger population. Because it is feasible to stop people with a family history of $\mathrm{VV}$ from working as a hairdresser or to implement protective measure since the early stage of their careers, findings in our study may help lowering the prevalence of lower limb VV in hairdressers.

Table 3 Lower limb varicose veins (VV) and work history by age group

\begin{tabular}{|c|c|c|c|c|c|}
\hline \multirow[t]{3}{*}{ Age (year) } & \multicolumn{4}{|c|}{ Work history } & \multirow[t]{3}{*}{$p$ value } \\
\hline & \multicolumn{2}{|c|}{ With VV } & \multicolumn{2}{|c|}{ Without VV } & \\
\hline & $\mathrm{N}$ & Year (SE) & $\mathrm{N}$ & Year (SE) & \\
\hline$\leq 35$ & 3 & $10.7(2.7)$ & 29 & $8.7(1.2)$ & 0.538 \\
\hline $36-45$ & 12 & $20.8(2.4)$ & 31 & $22.4(1.2)$ & 0.989 \\
\hline $46-55$ & 10 & $33.6(1.7)$ & 33 & $29.0(1.4)$ & 0.044 \\
\hline$>55$ & 15 & $41.1(1.9)$ & 28 & 35.7 (2.6) & 0.591 \\
\hline
\end{tabular}

*Mann-Whitney U test. 
Table 4 Multivariate logistic regression for hairdressers of age $\leq 45$ year-old

\begin{tabular}{lrrr}
\hline & N & $\begin{array}{r}\text { Odds } \\
\text { ratio }\end{array}$ & $\begin{array}{r}95 \% \text { confidence } \\
\text { interval }\end{array}$ \\
\hline Monthly standing work hours & 11 & 1.0 & \\
$6-120$ & 7 & 2.4 & $(0.1-55.6)$ \\
$121-168$ & 16 & 2.0 & $(0.2-24.2)$ \\
$169-208$ & 13 & 0.5 & $(0.0-11.3)$ \\
$209-260$ & 10 & 5.2 & $(0.4-75.8)$ \\
$261-360$ & & & \\
Number of years as a hairdresser & 20 & 1.0 & $(0.1-5.3)$ \\
$0-9$ & 19 & 0.6 & $(0.3-27.4)$ \\
$10-22$ & 18 & 2.7 & \\
$23-33$ & & & $(0.2-10.2)$ \\
Doing housework in standing position \\
No & 24 & 1.0 & \\
Yes & 33 & 1.5 & \\
Family history of varicose veins & & & \\
No & 52 & & $(1.1-133.5)^{*}$ \\
Yes & 5 & 11.9 & \\
${ }^{*} p<0.05$. & & &
\end{tabular}

Gender, body mass index, constipation, pregnancy, exercise, smoking, and drinking

Previous studies have identified female gender [7,9,10,13,14] and obesity $[7,9,13]$ as risk factors of $\mathrm{VV}$, and other reported factors included previous pregnancies [7,10,15-17], race [14], oral contraceptives $[11,16]$, trauma or injuries to

Table 5 Multivariate logistic regression for hairdressers of age $>45$ year-old

\begin{tabular}{|c|c|c|c|}
\hline & $\mathbf{N}$ & $\begin{array}{l}\text { Odds } \\
\text { ratio }\end{array}$ & $\begin{array}{r}95 \% \text { confidence } \\
\text { interval }\end{array}$ \\
\hline \multicolumn{4}{|c|}{ Monthly standing work hours } \\
\hline $25-120$ & 11 & 1.0 & \\
\hline $121-168$ & 13 & 9.7 & $(0.7-132.5)$ \\
\hline 169-208 & 12 & 7.4 & $(0.6-89.9)$ \\
\hline 209-260 & 10 & 6.4 & $(0.5-86.2)$ \\
\hline 261-360 & 9 & 31.8 & $(1.8-566.5)^{*}$ \\
\hline \multicolumn{4}{|c|}{ Number of years working as a hairdresser } \\
\hline $0-30$ & 20 & 1.0 & \\
\hline $31-42$ & 18 & 10.9 & $(1.6-73.8)^{*}$ \\
\hline $43-57$ & 17 & 12.0 & $(1.6-88.5)^{*}$ \\
\hline \multicolumn{4}{|c|}{ Doing housework in standing position } \\
\hline No & 8 & 1.0 & \\
\hline Yes & 47 & 0.9 & $(0.1-7.6)$ \\
\hline \multicolumn{4}{|c|}{ Family history of varicose veins } \\
\hline No & 42 & 1.0 & \\
\hline Yes & 13 & 1.6 & $(0.4-7.1)$ \\
\hline
\end{tabular}

lower limbs [9], constipation [7,16], and lower levels of activity [13] such as exercising less than once per week [15]. However, the effects of BMI, gender, times of childbirth, constipation, and regular exercise did not reach statistical significance in our study (Tables 1 and 2 ). The published data on the effects of smoking and drinking are limited. A large study on 1806 patients of lower limb venous insufficiency (not just VV) found that smoking more than 10 cigarettes per day was associated with a higher prevalence of venous insufficiency, but smoking less was not; none of the other factors related to smoking (tobacco quality, inhalation of smoke, use of filter, duration of smoking, etc.) was an independent predictor [18]. Alcohol abuse was not an independent risk factor for venous insufficiency in that study [18]. A study on VV exclusively, however, did not find smoking as a risk factor, but found a significant protective effect $(\mathrm{OR}=0.50)$ associated with moderate alcohol consumption ( $\leq 1$ drink/day) [19]. As the prevalence of both smoking and drinking is low in Taiwanese women and most hairdressers in Taiwan are women, the prevalence of both smoking and drinking was low in our participants. Neither factor was found to have a significant association with VV in our study.

\section{Work history}

Aging has been recognized as a major risk factor of VV $[2,3,7,9,10,14,20]$, but it usually correlates well with the length of work history. In our study, we tried to solve this problem by using stratified analyses according to age. We found the lengths of work history were similar (2 years apart or less) between participants with and without lower limb VV in the two younger age groups ( $\leq 35$ years and 36-45 years), but the difference was statistically significant in the 46-55 year-old group (a difference of 4.6 years). In the oldest group ( $\geq 55$ years), while a larger gap (5.4 years) was observed, the difference did not reach statistical significance, most likely due to the larger SE because of the larger age range covered in this group (Table 3). Therefore, in the multivariate analyses, we put the two older groups together and combined the two younger groups. As a result, we found that a long work history ( $>30$ years) was a significant risk factor in the older age group ( $>45$ years) (Table 5 ), but not in the younger age group ( $\leq 45$ years) (Table 4$)$.

\section{Prolonged standing at work and doing housework}

The effect of prolonged standing at work is the primary focus of this study. We found monthly standing work hours $(p=0.008)$ and doing housework in standing position $(p=0.042)$ were related to lower limb VV, but not weekly housework hours $(p=0.334)$.

A study conducted by Krijnen et al. [21] on 387 male European workers showed that the number of years of 
working in standing position was associated with the severity of chronic venous insufficiency, indicating working in standing position is an aggravating factor of lower limb VV. A study of female cotton workers also found a greater prevalence of VV in those who worked standing up [22]. In our study, after adjustment for other risk factors, the effect of prolonged standing at work did not reach statistical significance until standing for more than 260 hours each month in the older group. In the younger group, while standing for more than 260 hours each month was also associated with a higher risk $(\mathrm{OR}=5.2)$, the effect did not reach statistical significance, most likely due to insufficient statistical power (Table 4). The dose-response relationship between the number of hours standing at work and prevalence of lower limb VV was not obvious, and this might be attributable, at least in part, to a healthy worker effect [23], because some of the workers might choose to stand less often or even leave the job after acquiring VV.

After interviewing 2939 men and 2708 women aged 20-59 years old, a prospective study in Denmark found that during the 12 years of follow up, jobs requiring prolonged standing or walking were associated with a relative risk (RR) of 1.75 in men and 1.82 in women for hospitalizations due to VV $[24,25]$. Similar results were observed in a cross-sectional study in Germany which examined 9935 civil servants and found that after adjusting for age and gender, the OR for $\mathrm{VV}$ was 2.2 for standing at work [11]. A study in Austria on 209 hospital staff found that staffs with chronic venous disease stood longer at work, 4.4 vs. 2.7 hours per day in men and 3.9 vs. 3.2 hours per day in women [26]. The Framingham Study in the US observed a higher incidence of VV in women who reported spending 8 hours or more on sedentary activities (sitting or standing) than those who spent 4 hours or less a day $(p<0.05)$ [13]. In addition, a study of female workers in a large department store found a higher prevalence rate of severe $\mathrm{VV}$ among those who standing at work [17]. In summary, there are sufficient evidences supporting that prolonged standing at work or home is associated with the occurrence of lower limb VV.

\section{Methodological consideration}

Our study was based on self-administered questionnaires, and therefore over- or under-reporting of VV was possible. However, since the investigators had no influence on the employment of participants or their employers, there were no remarkable reasons for over- or underreporting of VV. Another potential limitation of using a questionnaire to assess $\mathrm{VV}$ is the validity of the selfreported condition. Laurikka et al. [27] studied this issue by comparing the results of mailed questionnaires to those of clinical examination with Doppler sonography and found a sensitivity of 0.92 and a specificity of 0.93 ; the estimated sensitivity and specificity for blue-collar workers were up to 0.96 and 0.94 respectively. In addition, the relatively small number of participants made further stratification of the study population difficult and thus limited our evaluations of more potential risk factors at the same time.

As the working days per month and the number of hours standing at work varied a lot, the hours of standing in working each month had a wide large. Hairdressers have different ways to do the same task. For example, some cut hairs in standing position most of the time while others do it in sitting position most of the time. In addition, the job contents varied: entry-level hairdressers usually spend a lot of time in washing hairs while senior hairdresser often spend most of the time cutting hairs. Furthermore, some hairdressers have good business and work more than 10 hours a day with little time to rest, while some others sit in the shops for long hours just waiting for customers. Therefore, there were many combinations of the number of work days per month and the number of hours standing at work per day, and we did not have enough participants in each situation for further analyses. In other words, we were unable to evaluate whether the number of work days per month, the number of hours standing at work per day, or both really mattered. Although the two critical variables-family history and hours of standing in working-had relatively large numbers of missing data information which reduced the statistical further, the effects still reached statistical significance.

\section{Conclusion}

In hairdressers $\leq 45$ years old, family history of VV is a major risk factor for developing lower limb VV, while in those who are $>45$ years old, the effects of occupational risk factors are more prominent. Therefore, preventive measures such as compression stockings and minimizing prolonged standing are recommended for workers with personal risk factors.

\section{Abbreviations}

BMl: Body mass index; Cl: Confidence interval; OR: Odds ratio; RR: Relative risk; SE: Standard error; W: Varicose veins.

\section{Competing interests}

The authors declare that they have no competing interests.

\section{Authors' contributions}

CLC and HRG conceived the study. HRG designed the study and CLC performed the data analysis. CLC drafted the manuscript, and HRG help revise it. Both authors read and approved the final manuscript.

\section{Acknowledgements}

This study was supported by a grant from the Council of Labor Affairs of the Taiwan government.

\section{Author details}

${ }^{1}$ Chest Hospital, Ministry of Health and Welfare, Tainan, Taiwan. ${ }^{2}$ Department of Occupational and Environmental Medicine, National Cheng Kung University Hospital, Tainan, Taiwan. ${ }^{3}$ Department of Environmental and Occupational Health, National Cheng Kung University, 138 Sheng-Li Road, 70428 Tainan, Taiwan. 
Received: 19 October 2013 Accepted: 18 August 2014

Published: 28 August 2014

\section{References}

1. Van den Oever R, Hepp B, Debbaut B, Simon I: Socio-economic impact of chronic venous insufficiency. An underestimated public health problem. Int Angiol 1998, 17:161-167.

2. Beebe-Dimmer JL, Pfeifer JR, Engle JS, Schottenfeld D: The epidemiology of chronic venous insufficiency and varicose veins. Ann Epidemiol 2005, 15:175-184

3. Robertson L, Evans C, Fowkes FG: Epidemiology of chronic venous disease. Phlebology 2008, 23:103-111.

4. Callam MJ: Epidemiology of varicose veins. Br J Surg 1994, 81:167-173.

5. Hirai M, Naiki K, Nakayama R: Prevalence and risk factors of varicose veins in Japanese women. Angiology 1990, 41:228-232.

6. Sun JM: Epidemiologic study on peripheral vascular diseases in Shanghai. Zhonghua Wai Ke Za Zhi 1990, 28:480-483. 510-481.

7. Jawien $\mathrm{A}$ : The influence of environmental factors in chronic venous insufficiency. Angiology 2003, 54(Suppl 1):S19-31.

8. Nassiri P, Golbabai F, Mahmoudi M: Occupational health problems of hairdressers of Tehran. Acta Med Iranica 1996, 34:14-16.

9. Lacroix P, Aboyans V, Preux PM, Houles MB, Laskar M: Epidemiology of venous insufficiency in an occupational population. Int Angiol 2003, 22:172-176.

10. Laurikka JO, Sisto T, Tarkka MR, Auvinen O, Hakama M: Risk indicators for varicose veins in forty- to sixty-year-olds in the Tampere varicose vein study. World J Surg 2002, 26:648-651.

11. Kroeger K, Ose C, Rudofsky G, Roesener J, Hirche H: Risk factors for varicose veins. Int Angiol 2004, 23:29-34.

12. Cornu-Thenard A, Boivin P, Baud JM, De Vincenzi I, Carpentier PH: Importance of the familial factor in varicose disease. Clinical study of 134 families. J Dermatol Surg Oncol 1994, 20:318-326.

13. Brand FN, Dannenberg AL, Abbott RD, Kannel WB: The epidemiology of varicose veins: the Framingham Study. Am J Prev Med 1988, 4:96-101.

14. Criqui MH, Jamosmos M, Fronek A, Denenberg JO, Langer RD, Bergan J, Golomb BA: Chronic venous disease in an ethnically diverse population: the San Diego Population Study. Am J Epidemiol 2003, 158:448-456.

15. Carpentier PH, Maricq HR, Biro C, Poncot-Makinen CO, Franco A: Prevalence, risk factors, and clinical patterns of chronic venous disorders of lower limbs: a population-based study in France. J Vasc Surg 2004, 40:650-659.

16. Fowkes FG, Lee AJ, Evans CJ, Allan PL, Bradbury AW, Ruckley CV: Lifestyle risk factors for lower limb venous reflux in the general population: Edinburgh Vein Study. Int J Epidemiol 2001, 30:846-852.

17. Stvrtinova V, Kolesar J, Wimmer G: Prevalence of varicose veins of the lower limbs in the women working at a department store. Int Angiol 1991, 10:2-5.

18. Gourgou S, Dedieu F, Sancho-Garnier H: Lower limb venous insufficiency and tobacco smoking: a case-control study. Am J Epidemiol 2002, 155:1007-1015.

19. Ahumada $M$, Vioque J: Prevalence and risk factors of varicose veins in adults. Med Clin 2004, 123:647-651.

20. Ruckley CV, Evans CJ, Allan PL, Lee AJ, Fowkes FG: Chronic venous insufficiency: clinical and duplex correlations. The Edinburgh Vein Study of venous disorders in the general population. J Vasc Surg 2002, 36:520-525

21. Krijnen RM, De Boer EM, Ader HJ, Bruynzeel DP: Venous insufficiency in male workers with a standing profession. Part 1: epidemiology. Dermatology 1997, 194:111-120.

22. Mekky S, Schilling RS, Walford J: Varicose veins in women cotton workers. An epidemiological study in England and Egypt. Br Med J 1969, 2:591-595.

23. $L i C Y$, Sung FC: A review of the healthy worker effect in occupational epidemiology. Occup Med (Lond) 1999, 49:225-229.

24. Tuchsen F, Krause N, Hannerz H, Burr H, Kristensen TS: Standing at work and varicose veins. Scand J Work Environ Health 2000, 26:414-420.

25. Tuchsen F, Hannerz $\mathrm{H}$, Burr $\mathrm{H}$, Krause N: Prolonged standing at work and hospitalisation due to varicose veins: a 12 year prospective study of the Danish population. Occup Environ Med 2005, 62:847-850.
26. Ziegler S, Eckhardt G, Stoger R, Machula J, Rudiger HW: High prevalence of chronic venous disease in hospital employees. Wien Klin Wochenschr 2003, 115:575-579.

27. Laurikka J, Laara E, Sisto T, Tarkka M, Auvinen O, Hakama M: Misclassification in a questionnaire survey of varicose veins. $J$ Clin Epidemiol 1995, 48:1175-1178.

doi:10.1186/1471-2458-14-885

Cite this article as: Chen and Guo: Varicose veins in hairdressers and associated risk factors: a cross-sectional study. BMC Public Health 2014 14:885.

\section{Submit your next manuscript to BioMed Central and take full advantage of:}

- Convenient online submission

- Thorough peer review

- No space constraints or color figure charges

- Immediate publication on acceptance

- Inclusion in PubMed, CAS, Scopus and Google Scholar

- Research which is freely available for redistribution 